\title{
Controlled Coordination in Vanadium(V) Dimethylhydrazido Compounds
}

\author{
Takashi Sakuramoto, Toshiyuki Moriuchi,* and Toshikazu Hirao* \\ Department of Applied Chemistry, Graduate School of Engineering, Osaka University, \\ Yamada-oka, Suita, Osaka 565-0871, Japan \\ moriuchi@chem.eng.osaka-u.ac.jp and hirao@chem.eng.osaka-u.ac.jp \\ Fax: +81-6-6879-7415
}

* to whom correspondence should be addressed 


\begin{abstract}
The vanadium $(\mathrm{V})$ dimethylhydrazido compounds were structurally characterized to elucidate the effect of the alkoxide ligands in the coordination environment of vanadium(V) hydrazido center. The single-crystal X-ray structure determination of the vanadium(V) dimethylhydrazido compound with isopropoxide ligands revealed a dimeric structure with the $\mathrm{V}(1)-\mathrm{N}(1)$ distance of $1.680(5) \AA$, in which each vanadium atom is coordinated in a distorted trigonal-bipyramidal geometry $\left(\tau_{5}=0.81\right)$ with the hydrazido and bridging isopropoxide ligands in the apical positions. On the contrary, nearly tetrahedral arrangement around the vanadium metal center $\left(\tau_{4}=0.06\right)$ with the $\mathrm{V}(1)-\mathrm{N}(1)$ distance of $1.660(2) \AA$ was observed in the vanadium(V) dimethylhydrazido compound with tert-butoxide ligands. The introduction of the $2,2^{\prime}, 2^{\prime \prime}$-nitrilotriethoxide ligand led to a pseudo-trigonal-bipyramidal geometry $\left(\tau_{5}=0.92\right)$ at the vanadium center with the V(1)-N(1) distance of 1.691(5) $\AA$, wherein vanadium atom is pulled out of the plane formed by the nitrilotriethoxide oxygen atoms in the direction of the hydrazido nitrogen. The coordination from the apical ligand in the vanadium(V) dimethylhydrazido compound was found to result in the longer V(1)-N(1) distance.
\end{abstract}

Keywords: Vanadium(V) hydrazido compound; Metal-nitrogen multiple; Self-association; Crystal structure; Controlled coordination environment 


\section{Introduction}

Metal hydrazido compounds have attracted much attention [1-4] because of their intermediacy in organic reactions such as hydrohydrazination [5-10], transformation to nitrogen heterocyclic compounds [8,10-15] and cleavage of N-N bond [8,10,16-25]. Furthermore, metal hydrazido complexes are regarded as intermediates of nitrogen fixation [1-3]. Although certain nitrogenases contain vanadium [1-3,26-28], hydrazido compounds of vanadium have received less attention [29-36]. The regulation of coordination environment of metal centers is considered to be a key factor for the control of reactivities of metal centers. We have already demonstrated the structural characterization of the vanadium(V) hydrazido compounds with the tris(2hydroxyphenyl)amine ligand to reveal the influence of the apical nitrogen and the substituent of the tris(2-hydroxyphenyl)amine ligand on the vanadium center [37]. Although vanadium(V) hydrazido compounds with phenoxide ligands have been investigated [33,36], vanadium(V) hydrazido compounds with alkoxide ligands have not been reported so far. Vanadium(V) imido compounds with alkoxide ligands are known to self-associate through $\mu$-alkoxido-bridging [3845]. The hydrazido and imido ligands coordinate through a metal-nitrogen multiple bond [46-47]. The $p$-substituent on the benzene rings of vanadium(V) arylimido compounds with isopropoxide ligands have been demonstrated to control the nature of the imido bonds through $\pi$-conjugation [41-44,48-49], which regulates the self-association properties to form the $\mu$-isopropoxidobridging or the $\mu$-arylimido-bridging dinuclear compounds [41]. The self-association properties of vanadium(V) hydrazido compounds are expected to be controlled by the steric effects of alkoxide ligands. From these points of view, we herein report the controlled coordination environments of the vanadium(V) dimethylhydrazido compounds by using the ancillary alkoxide ligands. 


\section{Results and Discussion}

Isopropoxide and tert-butoxide ligands were focused on as the ancillary alkoxide ligand. To regulate the self-association, 2,2',2"-nitrilotriethoxide was used as a four-coordinating ligand wherein three oxygens are expected to coordinate to metal center in the equatorial position and nitrogen might occupy the apical position [50]. The reaction of $\operatorname{VO}\left(\mathrm{O}^{i} \operatorname{Pr}\right)_{3}$ with $N, N$ dimethylhydrazine in dichloromethane at room temperature afforded the corresponding vanadium(V) dimethylhydrazido compound 1a with isopropoxide ligands as shown in Scheme 1. The vanadium $(\mathrm{V})$ dimethylhydrazido compound $\mathbf{1 b}$ with tert-butoxide ligands was similarly obtained by the $\operatorname{VO}\left(\mathrm{O}^{t} \mathrm{Bu}\right)_{3}$ with $N, N$-dimethylhydrazine in toluene at $100{ }^{\circ} \mathrm{C}$. The ligand exchange reaction of the vanadium(V) dimethylhydrazido compound 1a with 2,2',2"nitrilotriethanol in dichloromethane at room temperature led to the formation of the vanadium $(\mathrm{V})$ dimethylhydrazido compound 2a with the nitrilotriethoxide ligand.

[Insert Scheme 1]

Thus-obtained vanadium(V) dimethylhydrazido compounds were fully characterized by spectral data and X-ray crystallographic analyses. The ligand effect on the electronic environment

of the vanadium center was examined by ${ }^{51} \mathrm{~V}$ NMR measurements. The ${ }^{51} \mathrm{~V}$ chemical shift of the vanadium(V) dimethylhydrazido compound 1a with isopropoxide ligands was detected at -394 ppm. In the ${ }^{51} \mathrm{~V}$ NMR spectrum of the vanadium(V) dimethylhydrazido compound $\mathbf{1 b}$ with tertbutoxide ligands, ${ }^{51} \mathrm{~V}$ chemical shift was observed at $-436 \mathrm{ppm} .{ }^{51} \mathrm{~V}$ chemical shift was found to be observed at the higher field with increase of the electron-donating capability of the ligands [37]. On the contrary, the vanadium(V) dimethylhydrazido compound 2a with the nitrilotriethoxide ligand showed ${ }^{51} \mathrm{~V}$ chemical shift at $-23 \mathrm{ppm}$, probably due to the donor ability 
of the nitrilotriethoxide nitrogen. These results are consistent with the reported data of the oxovanadium(V) nitrilotriethoxide [50]. The ancillary alkoxide ligands were found to influence the electron density of the vanadium center directly.

X-ray crystallographic analyses were performed in order to clarify the coordination environment of the vanadium(V) center and self-association properties of the vanadium(V) dimethylhydrazido compounds (Table 1). The important bond lengths and angles are listed in Table 2. Diffraction-quality single crystal of the vanadium(V) dimethylhydrazido compound 1a with isopropoxide ligands was grown by diffusion of hexane into dichloromethane solution of 1a. The crystal structure of 1a revealed the hydrazido structure with the $\mathrm{V}(1)-\mathrm{N}(1)$ distance of $1.680(5) \AA$, the $\mathrm{N}(1)-\mathrm{N}(2)$ distance of $1.321(8) \AA$ and the nearly linear $\mathrm{V}(1)-\mathrm{N}(1)-\mathrm{N}(2)$ angle of $176.9(5)^{\circ}$ (Fig. 1), suggesting the high participation of an sp-hybridized character in the nitrogen of the V-N bond. A dimeric structure, in which each vanadium atom is coordinated in a distorted trigonal-bipyramidal geometry with the hydrazido and bridging isopropoxide ligands in apical positions as observed with oxovanadium(V) alkoxides [51], is formed in the crystal packing as depicted in Fig. 1. The structural parameter $\tau_{5}$ for the coordination geometry of the fivecoordinated complex proposed by Addison and Reedijik shows $\tau_{5}=0.81$ for 1a [52]. The parameters for an ideal square pyramidal and trigonal bipyramidal geometries are $\tau_{5}=0$ and $\tau_{5}=$ 1, respectively. The $\tau_{5}$ value of 1 a supports a distorted trigonal-bipyramidal geometry at the vanadium center. The V(1)-V(1a) internuclear distance of 3.284(1) A suggests the absence of any bonding interaction between the vanadium centers. The axial $\mathrm{V}(1)-\mathrm{O}(1 \mathrm{a})$ bond is $0.28 \AA$ longer than the equatorial $\mathrm{V}(1)-\mathrm{O}(1)$ bond in the bridging isopropoxy group. The long apical $\mathrm{V}-\mathrm{O}$ distance trans to the hydrazido ligand indicates a weaker coordination. In the ${ }^{1} \mathrm{H}$ NMR spectrum of $\mathbf{1 a}$ in $\mathrm{CD}_{2} \mathrm{Cl}_{2}$, only one kind of isopropyl resonance was observed, suggesting that $\mathbf{1 a}$ is likely to be monomeric in a solution state. 
[Insert Table 1]

[Insert Table 2]

[Insert Fig. 1]

Recrystallization of the vanadium(V) dimethylhydrazido compound $\mathbf{1 b}$ with tert-butoxide ligands from hexane gave single crystals suitable for single-crystal X-ray structure determination. The structural parameter $\tau_{4}$ for the coordination geometry of the four-coordinated complex proposed by Vela and Holland [53], wherein the parameters for an ideal tetrahedral complex and trigonal pyramid geometries are $\tau_{4}=0$ and $\tau_{4}=1$, respectively, is 0.06 for $\mathbf{1 b}$. The $\tau_{4}$ value of $\mathbf{1 b}$ indicates that the coordination geometry around the vanadium atom is almost tetrahedral as shown in Fig. 2. Bulky tert-butoxide ligands might prevent the self-association, resulting in a tetrahedral monomeric structure. The hydrazido structure with the $\mathrm{V}(1)-\mathrm{N}(1)$ distance of $1.660(2)$ $\AA$, the $\mathrm{N}(1)-\mathrm{N}(2)$ distance of $1.316(4) \AA$, and the nearly linear $\mathrm{V}(1)-\mathrm{N}(1)-\mathrm{N}(2)$ angle of $176.0(3)^{\circ}$ indicate the strong $\pi$ donation from nitrogen to vanadium center and the higher participation of an sp-hybridized character in the nitrogen atom of the V-N bond. The V(1)-N(1) distance of 1a is $0.02 \AA$ longer than that of $\mathbf{1 b}$. The electron donation from hydrazido nitrogen to the vanadium center is considered to be weaken to some extent, probably due to the coordination from apical oxygen in the case of the $\mu$-isopropoxido-bridging dimeric structure.

[Insert Fig. 2]

Single crystals of $\mathbf{2 a}$ suitable for single-crystal X-ray structure determination were obtained by diffusion of ether into dichloromethane solution of $\mathbf{2 a}$. From the result of the X-ray crystallographic analysis, the introduction of the nitrilotriethoxide ligand was found to lead to a pseudo-trigonal-bipyramidal geometry $\left(\tau_{5}=0.92\right)[52]$ at the vanadium center with an equatorial 
nitrilotriethoxide oxygen atoms, wherein vanadium atom is pulled out of the plane formed by the nitrilotriethoxide oxygen atoms in the direction of the hydrazido nitrogen, as depicted in Fig. 3. The V(1)-N(1) distance of 1.691(5) $\AA$, the N(1)-N(2) distance of 1.311(7) $\AA$, and the V(1)-N(1)$\mathrm{N}(2)$ angle of $172.8(4)^{\circ}$ were observed in the hydrazido structure of $\mathbf{2 a}$. The coordination from apical nitrogen in the vanadium(V) dimethylhydrazido compounds was found to lengthen the $\mathrm{V}(1)-\mathrm{N}(1)$ distance. The longer $\mathrm{V}-\mathrm{N}$ bond and more bent $\mathrm{V}(1)-\mathrm{N}(1)-\mathrm{N}(2)$ angle of $\mathbf{2 a}$ as compared with 1a and $\mathbf{1 b}$ might be due to the donor ability of the nitrilotriethoxide nitrogen. It should be noted that $\mathrm{N}(1)-\mathrm{N}(2)$ distance was found to be affected by the twist angle $\beta$ defined as the angle between the least-squares plane of $\mathrm{V}(1)-\mathrm{N}(1)-\mathrm{N}(2)$ and that of $\mathrm{C}\left(\mathrm{Me}^{\mathrm{a}}\right)-\mathrm{C}\left(\mathrm{Me}^{\mathrm{b}}\right)-\mathrm{N}(1)$ (Fig. 4), which is considered to correlate to the conjugation properties of hydrazido ligands. The crystal structure of 2a showed a nearly parallel twist angle $\beta$ of $11.0^{\circ}$ with the $\mathrm{N}(1)-\mathrm{N}(2)$ distance of 1.311(7) A. On the contrary, an almost perpendicular twist angle $\beta$ of $89.0^{\circ}$ was observed in 1a, which has longer $\mathrm{N}(1)-\mathrm{N}(2)$ distance of 1.321(8) $\AA$ as compared with 2a. A nearly parallel twist angle of 2a indicates the conjugation of lone pair on $\mathrm{N}(2)$ with the filled $\mathrm{V}(1)-\mathrm{N}(1)$ imido $\pi$ orbital, which might induce the shorter N(1)-N(2) distance of 2a. From an almost perpendicular twist angle $\beta$ of 1a, the electrostatic repulsion between lone pairs of $\mathrm{N}(1)$ and $\mathrm{N}(2)$ is likely to induce longer $\mathrm{N}(1)-\mathrm{N}(2)$ distance. The twist angle $\beta$ of $48.9^{\circ}$ in $\mathbf{1 b}$ shows the weakened conjugation in the hydrazido moiety with longer $\mathrm{N}(1)-\mathrm{N}(2)$ distance as compared with $\mathbf{2 a}$.

[Insert Fig. 3]

[Insert Fig. 4] 


\section{Conclusions}

In conclusion, structural characterization of vanadium(V) dimethylhydrazido compounds with the ancillary alkoxide ligands were demonstrated to gain insight into the coordination environments of vanadium-nitrogen multiple bond and self-association properties. Coordination environments of vanadium( $(\mathrm{V})$ dimethylhydrazido compounds were found to be controlled by changing the alkoxide ligands. The vanadium(V) dimethylhydrazido compound with isopropoxide ligands was performed to self-associate through the $\mu$-isopropoxido-bridging to a distorted trigonal-bipyramidal geometry with the hydrazido and bridging isopropoxide ligands in apical positions although bulky tert-butoxide ligands led to a tetrahedral monomeric structure. Vanadium compounds are known to be potent inhibitors of phosphatases, wherein vanadiumphosphatase complexes have the vanadium in a five-coordinate geometry [54-57]. In the evaluation of the inhibitors, initial coordination geometry of vanadium compounds plays an important role. The control of coordination geometry in this study is expected to be applied to phosphatase inhibitors. The introduction of the nitrilotriethoxide ligand was found to afford a pseudo-trigonal-bipyramidal monomeric structure. The coordination from apical position to the vanadium center was also performed to weaken the $\mathrm{V}-\mathrm{N}$ multiple bond, wherein the hydrazido structure depends on the donor ability of the apical ligand. Oxovanadium(V) compounds are known to show a variety of reactivities in organic synthesis [58]. Imidovanadium(V) compounds have been also demonstrated to induce the selective oxidative coupling reaction of silyl ketene acetal and silyl enol ether [43]. Control of coordination environments of vanadium(V) dimethylhydrazido compounds is considered to be a key factor in the design of catalysts. Further investigation on the control of the hydrazido structures and the application of the vanadium(V) hydrazido complexes for catalysis are now in progress. 


\section{Experimental}

\subsection{General materials and experimental procedures}

All manipulations were carried out under an atmosphere of nitrogen in a Vacuum Atmospheres drybox. All reagents and solvents were purchased from commercial sources and were further purified by the standard methods, if necessary. Solvents employed were dried by refluxing in the presence of appropriate drying reagents, distilled under an atmosphere of nitrogen, and were stored in the drybox. ${ }^{1} \mathrm{H}$ NMR spectra were recorded on a JEOL JNM-ECP $400(400 \mathrm{MHz})$ spectrometer. The chemical shifts were referenced to the residual resonances of

deuterated solvents. ${ }^{51} \mathrm{~V}$ NMR spectra were obtained with a JEOL JNM-ECP 400 (105 MHz) spectrometer with $\mathrm{VOCl}_{3}$ as an external standard.

Vanadium $(\mathrm{V})$ oxytri-tert-butoxide $\left(\mathrm{VO}\left(\mathrm{O}^{t} \mathrm{Bu}\right)_{3}\right)$ was prepared by the literature methods [59].

\subsubsection{Synthesis of (dimethylhydrazido)vanadium(V) triisopropoxide (1a)}

A mixture of $\mathrm{VO}\left(\mathrm{O}^{i} \mathrm{Pr}\right)_{3}(0.24 \mathrm{~mL}, 1.0 \mathrm{mmol}), N, N$-dimethylhydrazine $(76 \mu \mathrm{L}, 1.0 \mathrm{mmol})$, and $\mathrm{NaH}(24 \mathrm{mg}, 1.0 \mathrm{mmol})$ was stirred in dichloromethane $(10 \mathrm{~mL})$ under an atmosphere of nitrogen in a drybox at room temperature for $18 \mathrm{~h}$. The resulting solution was filtered off, and the filtrate was evaporated under a reduced pressure. The resulting red-brown solid was extracted with hexane and the solvent was removed in vacuo to give the red-brown solid. The desired (dimethylhydrazido)vanadium(V) triisopropoxide (1a) was isolated as a reddish brown crystal $(0.13 \mathrm{~g}, 0.45 \mathrm{mmol})$ by recrystallization from dichloromethane/hexane at $-30{ }^{\circ} \mathrm{C}$. 
1a: yield 45\%; ${ }^{1} \mathrm{H}$ NMR (400 MHz, $\left.\mathrm{CD}_{2} \mathrm{Cl}_{2}\right) \delta 5.04$ (sept, $3 \mathrm{H}, J=6.0 \mathrm{~Hz}$ ), 3.05 (s, $6 \mathrm{H}$ ), $1.30(\mathrm{~d}, 18 \mathrm{H}, J=6.0 \mathrm{~Hz}) ;{ }^{13} \mathrm{C} \mathrm{NMR}\left(100 \mathrm{MHz}, \mathrm{CD}_{2} \mathrm{Cl}_{2}\right) 78.8,47.1,27.2 \mathrm{ppm} ;{ }^{51} \mathrm{~V}$ NMR $(105$ $\left.\mathrm{MHz}, \mathrm{CD}_{2} \mathrm{Cl}_{2}\right)-393 \mathrm{ppm}$.

\subsubsection{Synthesis of (dimethylhydrazido)vanadium(V) tri-tert-butoxide (1b)}

A mixture of $\mathrm{VO}\left(\mathrm{O}^{t} \mathrm{Bu}\right)_{3}(0.29 \mathrm{~g}, 1.0 \mathrm{mmol}), N, N$-dimethylhydrazine $(76 \mu \mathrm{L}, 1.0 \mathrm{mmol})$, and $\mathrm{NaH}(48 \mathrm{mg}, 2.0 \mathrm{mmol})$ was stirred in toluene $(4 \mathrm{~mL})$ under an atmosphere of nitrogen in a drybox at $100{ }^{\circ} \mathrm{C}$ for $18 \mathrm{~h}$. The resulting solution was filtered off, and the filtrate was evaporated under a reduced pressure. The resultant residue was purified by reprecipitation from hexane at $30{ }^{\circ} \mathrm{C}$. Thus-obtained solid was recrystallized from hexane at $-30{ }^{\circ} \mathrm{C}$, giving the desired (dimethylhydrazido)vanadium(V) tri-tert-butoxide (1b) as a reddish brown crystal $(0.11 \mathrm{~g}, 0.33$ mmol).

1b: yield 33\%; ${ }^{1} \mathrm{H}$ NMR $\left(400 \mathrm{MHz}, \mathrm{CD}_{2} \mathrm{Cl}_{2}\right) \delta 3.10(\mathrm{~s}, 6 \mathrm{H}), 1.38(\mathrm{~s}, 27 \mathrm{H}) ;{ }^{13} \mathrm{C}$ NMR $(100$ $\left.\mathrm{MHz}, \mathrm{CD}_{2} \mathrm{Cl}_{2}\right) 79.2,46.9,33.0 ;{ }^{51} \mathrm{~V}$ NMR $\left(105 \mathrm{MHz}, \mathrm{CD}_{2} \mathrm{Cl}_{2}\right)-436 \mathrm{ppm}$.

\subsubsection{Synthesis of (dimethylhydrazido)vanadium(V) nitrilotriethoxide (2a)}

A mixture of 1a (43 mg, $0.15 \mathrm{mmol})$ and 2,2',2"-nitrilotriethanol (27 mg, $0.18 \mathrm{mmol})$ was stirred in dichloromethane $(15 \mathrm{~mL})$ under an atmosphere of nitrogen in a drybox at room temperature for $3 \mathrm{~h}$. The resulting solution was filtered off, and the filtrate was evaporated under a reduced pressure. The resultant residue was washed with ether. Thus-obtained solid was recrystallized from dichloromethane/ether at room temperature, giving the desired (dimethylhydrazido)vanadium(V) nitrilotriethoxide (2a) as a reddish brown crystal (33 $\mathrm{mg}, 0.13$ mmol). 
2a: yield 87\%; ${ }^{1} \mathrm{H}$ NMR (400 MHz, $\left.\mathrm{CD}_{2} \mathrm{Cl}_{2}\right) \delta 4.52(\mathrm{t}, 6 \mathrm{H}, J=5.5 \mathrm{~Hz}), 3.19(\mathrm{~s}, 6 \mathrm{H}), 2.88$ $(\mathrm{t}, 6 \mathrm{H}, J=5.5 \mathrm{~Hz}) ;{ }^{13} \mathrm{C} \mathrm{NMR}\left(100 \mathrm{MHz}, \mathrm{CD}_{2} \mathrm{Cl}_{2}\right) 71.2,54.2,44.2 ;{ }^{51} \mathrm{~V} \mathrm{NMR}(105 \mathrm{MHz}$, $\left.\mathrm{CD}_{2} \mathrm{Cl}_{2}\right)-23 \mathrm{ppm}$.

\section{2. $X$-ray structure analysis}

All measurements for $\mathbf{1 a}, \mathbf{1 b}$, and $\mathbf{2 a}$ were made on a Rigaku R-AXIS RAPID diffractometer using graphite monochromated $\operatorname{MoK} \alpha$ radiation. The structures of $\mathbf{1 a}, \mathbf{1 b}$, and 2a were solved by direct methods [60] and expanded using Fourier techniques. All calculations were performed using the CrystalStructure crystallographic software package [61] except for the refinement, which was performed using SHELXL-97 [62]. The non-hydrogen atoms were refined anisotropically. The $\mathrm{H}$ atoms were placed in idealized positions and allowed to ride with the $\mathrm{C}$ atoms to which each was bonded. Crystallographic details are given in Table 1. Crystallographic data (excluding structure factors) for the structures reported in this paper have been deposited with the Cambridge Crystallographic Data Centre as supplementary publication no. CCDC1437310 for 1a, CCDC-1437311 for 1b, and CCDC-1437312 for 2a. Copies of the data can be obtained free of charge on application to CCDC, 12 Union Road, Cambridge CB2 1EZ, UK [Fax: (internat.)+44-1223/336-033; E-mail: deposit@ccdc.cam.ac.uk].

\section{Acknowledgment.}

This work was supported by ACT-C, JST. Thanks are due to the Analytical Center, Graduate School of Engineering, Osaka University.. 


\section{Appendix A. Supplementary material}

Crystallographic data (excluding structure factors) for $\mathbf{1 a}, \mathbf{1 b}$, and $\mathbf{2 a}$ have been deposited with the Cambridge Crystallographic Data Centre as supplementary publication no. CCDC1437310 for 1a, CCDC-1437311 for 1b, and CCDC-1437312 for 2a. Copies of the data can be obtained free of charge on application to CCDC, 12 Union Road, Cambridge CB2 1EZ, UK [Fax: (internat.)+44-1223/336-033; E-mail: deposit@ccdc.cam.ac.uk]. 


\section{References and Notes.}

[1] D. Sutton, Chem. Rev. 93 (1993) 995-1022.

[2] M. Hidai, Y. Mizobe, Chem. Rev. 95 (1995) 1115-1133.

[3] B. A. MacKay, M. D. Fryzuk, Chem. Rev. 104 (2004) 385-401.

[4] R. R. Schrock, Acc. Chem. Res. 38 (2005) 955-962.

[5] C. Cao, Y. Shi, A. L. Odom, Org. Lett. 4 (2002) 2853-2856.

[6] Y. Li, Y. Shi, A. L. Odom, J. Am. Chem. Soc. 126 (2004) 1794-1803.

[7] A. Tillack, H. Jiao, I. Garcia Castro, C. G. Hartung, M. Beller, Chem. Eur. J. 10 (2004) 2409-2420.

[8] A. L. Odom, Dalton Trans. (2005) 225-233.

[9] A. D. Schwarz, C. S. Onn, P. Mountford, Angew. Chem. Int. Ed. 51 (2012) 12298-12302.

[10] A. L. Odom, T. J. McDaniel, Acc. Chem. Res. 48 (2015) 2822-2833.

[11] P. J. Walsh, M. J. Carney, R. G. Bergman, J. Am. Chem. Soc. 113 (1991) 6343-6345.

[12] H. Seino, Y. Ishii, M. Hidai, J. Am. Chem. Soc. 116 (1994) 7433-7434.

[13] H. Seino, Y. Ishii, T. Sasagawa, M. Hidai, J. Am. Chem. Soc. 117 (1995) 12181-12193.

[14] H. Seino, Y. Ishii, M. Hidai, Inorg. Chem. 36 (1997) 161-171.

[15] T. Gehrmann, J. Lloret Fillol, S. A. Scholl, H. Wadepohl, L. H. Gade, Angew. Chem. Int. Ed. 2011, 50 (2011) 5757-5761.

[16] C. J. Pickett, G. J. Leigh, J. Chem. Soc., Chem. Commun. (1981) 1033-1035.

[17] M. M. Baum, E. H. Smith, J. Chem. Soc., Perkin Trans. 1. (1993) 2513-2519.

[18] J. D. Selby, C. D. Manley, M. Feliz, A. D. Schwarz, E. Clot, P. Mountford, Chem. Commun. (2007) 4937-4939.

[19] H. Herrmann, J. Lloret Fillol, H. Wadepohl, L. H. Gade, Angew. Chem. Int. Ed. 46 (2007) 8426-8430. 
[20] D. J. Mindiola, Angew. Chem. Int. Ed. 47 (2008) 1557-1559.

[21] M. Yuki, Y. Miyake, Y. Nishibayashi, Organometallics 28 (2009) 5821-5827.

[22] Z. Huang, J. Zhou, J. F. Hartwig, J. Am. Chem. Soc. 132 (2010) 11458-11460.

[23] S. A. DiFranco, R. J. Staples, A. L. Odom, Dalton Trans. 42 (2013) 2530-2539.

[24] J. Unruangsri, H. Morgan, A. D. Schwarz, A. D. Schofield, P. Mountford, Organometallics 32 (2013) 3091-3107.

[25] T. Gehrmann, J. Lloret Fillol, H. Herrmann, H. Wadepohl, L. H. Gade, Organometallics 32 (2013) 3877-3889.

[26] T. A. Bazhenova, A. E. Shilov, Coord. Chem. Rev. 144 (1995) 69-145.

[27] R. R. Eady, Chem. Rev. 96 (1996) 3013.

[28] D. Rehder, Coord. Chem. Rev. 182 (1999) 297-322.

[29] N. Wiberg, H.-W. Häring, G. Huttner, P. Friedrich, Chem. Ber. 111 (1978) 2708-2715.

[30] J. Bultitude, L. F. Larkworthy, D. C. Povey, G. W. Smith, J. R. Dilworth, G. J. Leigh, J. Chem. Soc., Chem. Commun. (1986) 1748-1750.

[31] C. Le Floc'h, R. A. Henderson, D. L. Hughes, R. L. Richards, J. Chem. Soc., Chem. Commun. (1993) 175-176.

[32] S. C. Davies, D. L. Hughes, Z. Janas, L. Jerzykiewicz, R. L. Richards, J. R. Sanders, P. Sobota, Chem. Commun. (1997) 1261-1262.

[33] R. A. Henderson, Z. Janas, L. B. Jerzykiewicz, R. L. Richards, P. Sobota, Inorg. Chim. Acta 285 (1999) 178-183.

[34] S. C. Davies, D. L. Hughes, Z. Janas, L. B. Jerzykiewicz, R. L. Richards, J. R. Sanders, J. E. Silverston, P. Sobota, Inorg. Chem. 39 (2000) 3485-3498.

[35] S. C. Davies, D. L. Hughes, M. Konkol, R. L. Richards, J. R. Sanders, P. Sobota, J. Chem. Soc., Dalton Trans. (2002) 2811-2814.

[36] S. Banerjee, A. L. Odom, Dalton Trans. (2008) 2005-2008. 
[37] T. Moriuchi, K. Ikeuchi, T. Hirao, Dalton Trans. 42 (2013) 11824-11830.

[38] D. D. Devore, J. D. Lichtenhan, F. Takusagawa, E. A. Maatta, J. Am. Chem. Soc. 109 (1987) 7408-7416.

[39] M. Lutz, H. Hagen, A. M. M. Schreurs, A. L. Spek, G. van Koten, Acta Cryst. C55 (1999) 1636-1639.

[40] T. Moriuchi, K. Ishino, T. Hirao, Chem. Lett. (2007) 1486-1487.

[41] T. Moriuchi, K. Ishino, T. Beppu, M. Nishina, T. Hirao, Inorg. Chem. 47 (2008) 76387643.

[42] T. Moriuchi, T. Hirao, Pure Appl. Chem. 81 (2009) 1187-1195.

[43] M. Nishina, T. Moriuchi, T. Hirao, Dalton Trans. 39 (2010) 9936-9940.

[44] T. Moriuchi, T. Hirao, Coord. Chem. Rev. 255 (2011) 2371-2377.

[45] M. Nishina, T. Moriuchi, T. Hirao, Bull. Chem. Soc. Jpn. 85 (2012) 606-612.

[46] W. A. Nugent, J. M. Mayer, Metal-Ligand Multiple Bonds, Wiley-Interscience, New York, 1998.

[47] T. R. Cundari, Chem. Rev. 100 (2000) 807-818.

[48] T. Moriuchi, M. Nishina, T. Hirao, Angew. Chem. Int. Ed. Engl. 49 (2010) 83-86.

[49] T. Moriuchi, T. Beppu, K. Ishino, M. Nishina, T. Hirao, Eur. J. Inorg. Chem. 12 (2008) 1969-1973.

[50] D. C. Crans, H. Chen, O. P. Anderson, M. M. Miller, J. Am. Chem. Soc. 115 (1993) 6769-6776.

[51] D. C. Crans, R. A. Felty, M. M. Miller, J. Am. Chem. Soc. 113 (1991) 265-269.

[52] The structural parameter $\tau_{5}=(\beta-\alpha) / 60$ for the coordination geometry of the fivecoordinated complex was proposed by Addison and Reedijik where $\beta$ and $\alpha$ represent two basal angles $(\beta>\alpha)$. The parameters for an ideal square pyramidal and trigonal bipyramidal geometries are $\tau_{5}=0\left(\alpha=\beta=180^{\circ}\right)$ and $\tau_{5}=1\left(\alpha=120^{\circ}\right.$ and $\left.\beta=180^{\circ}\right)$, 
respectively. A. W. Addison, T. N. Rao, J. Reedijk, J. van Rijn, G. C. Verschoor, J. Chem. Soc. Dalton Trans. (1984) 1349-1356.

[53] The structural parameter $\tau_{4}=\{\Sigma$ (basal-M-basal) $-\Sigma($ basal-M-axial $)\} / 90$ for the coordination geometry of the four-coordinated complex was proposed by Vela and Holland. The parameters for an ideal tetrahedral complex and trigonal pyramid geometries are $\tau_{4}=[(109.5 \times 3)-(109.5 \times 3)] / 90=0$ and $\tau_{4}=[(120 \times 3)-(90 \times 3)] / 90=1$, respectively. J. Vela, S. Stoian, C. J. Flaschenriem, E. Munck, P. L. Holland, J. Am. Chem. Soc. 126 (2004) 4522-4523.

[54] D. C. Crans, R. L. Bunch, L. A. Theisen, J. Am. Chem. Soc. 111 (1989) 7597-7607.

[55] C. C. McLauchlan, J. D. Hooker, M. A. Jones, Z. Dymon, E. A. Backhus, B. A. Greiner, N. A. Dorner, M. A. Youkhana, L. M. Manus, J. Inorg. Biochem. 104 (2010) 274-281.

[56] C. C. McLauchlan, B. J. Peters, G. R. Willsky, D. C. Crans, Coord. Chem. Rev. 301-302 (2015) 163-199.

[57] D. C. Crans, J. Org. Chem. 80 (2015) 11899-11915.

[58] T. Hirao, Chem. Rev. 97 (1997) 2707-2724.

[59] L. P. Stepovika, M. V. Gulenovaa, A. N. Tishkinab, V. K. Cherkasov, Russ. J. Gen. Chem. 77 (2007) 1254-1262.

[60] M. C. Burla, R. Caliandro, M. Camalli, B. Carrozzini, G. L. Cascarano, L. De Caro, C. Giacovazzo, G. Polidori, R. Spagna, J. Appl. Cryst. 38 (2005) 381-388.

[61] CrystalStructure 4.1: Crystal Structure Analysis Package, Rigaku Corporation (20002014). Tokyo 196-8666, Japan.

[62] G. M. Sheldrick, Acta Crystallogr. Sec. A. 64 (2008) 112-122. 


\section{Figure Captions}

Fig. 1. The $\mu$-isopropoxido-bridged dimeric structure of $1 \mathbf{a}$ in the crystal structure (40\% probability ellipsoids; hydrogen atoms are omitted for clarity).

Fig. 2. Crystal structure of $\mathbf{1 b}$ (40\% probability ellipsoids; hydrogen atoms are omitted for clarity).

Fig. 3. Crystal structure of 2a (40\% probability ellipsoids; hydrogen atoms are omitted for clarity).

Fig. 4. The twist angle $\beta$ defined as the angle between the least-squares plane of V(1)-N(1)$\mathrm{N}(2)$ and that of $\mathrm{C}\left(\mathrm{Me}^{\mathrm{a}}\right)-\mathrm{C}\left(\mathrm{Me}^{\mathrm{b}}\right)-\mathrm{N}(1)$. 

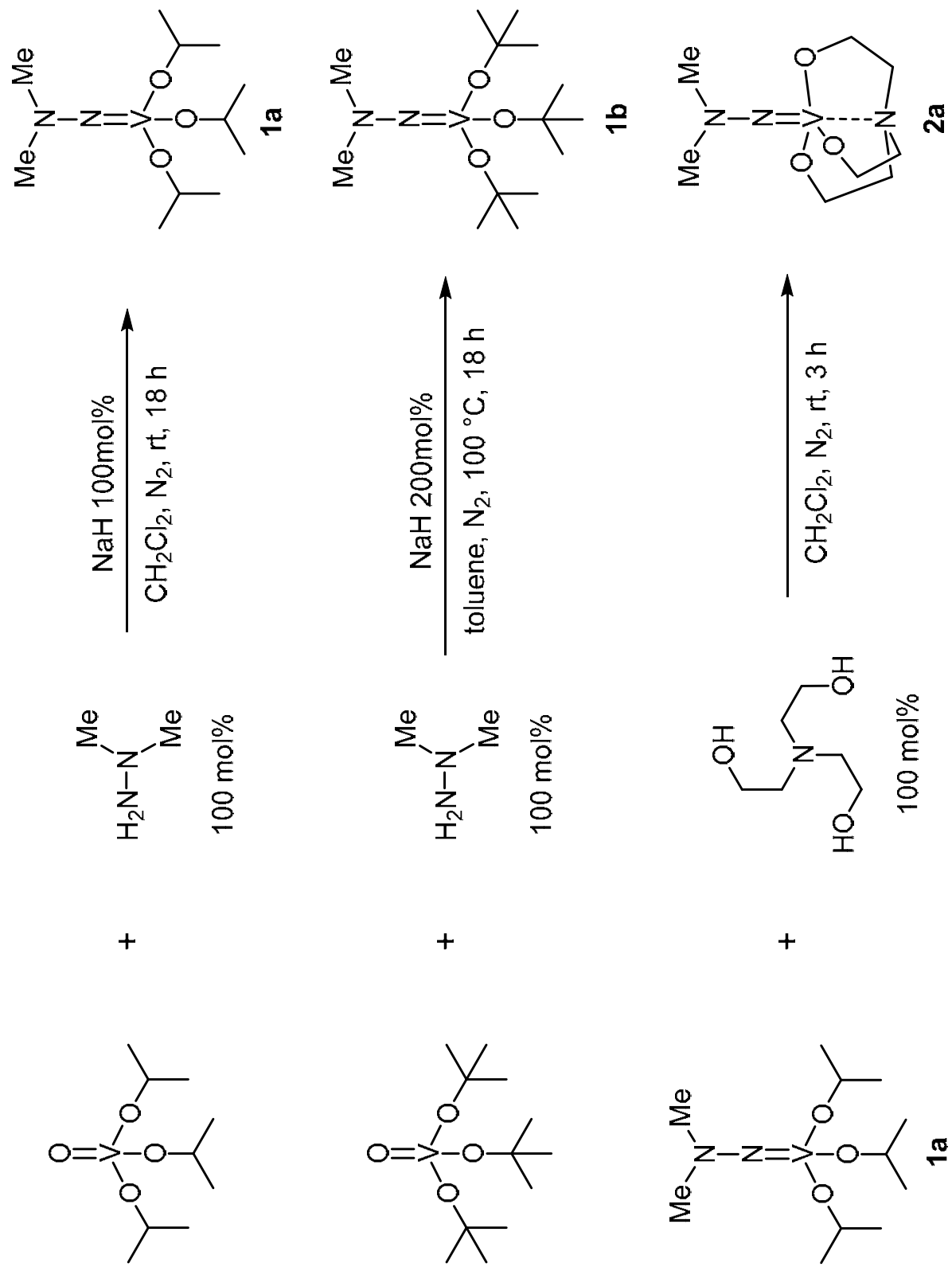
Table 1.

Crystallographic date for $\mathbf{1 a}, \mathbf{1 b}$, and $\mathbf{2 a}$

\begin{tabular}{llll}
\hline & $\mathbf{1 a}$ & $\mathbf{1 b}$ & $\mathbf{2 a}$ \\
\hline Empirical formula & $\mathrm{C}_{11} \mathrm{H}_{27} \mathrm{~N}_{2} \mathrm{O}_{3} \mathrm{~V}$ & $\mathrm{C}_{14} \mathrm{H}_{33} \mathrm{~N}_{2} \mathrm{O}_{3} \mathrm{~V}$ & $\mathrm{C}_{8} \mathrm{H}_{18} \mathrm{~N}_{3} \mathrm{O}_{3} \mathrm{~V}$ \\
Formula weight & 286.29 & 328.37 & 255.19 \\
Crystal system & triclinic & orthorhombic & triclinic \\
Space group & $P-1$ (No. 2) & Pbca (No. 61) & $P-1$ (No. 2) \\
$a(\AA)$ & $8.2396(12)$ & $14.6263(8)$ & $8.1393(6)$ \\
$b(\AA)$ & $10.1491(14)$ & $15.0292(9)$ & $8.8157(7)$ \\
$c(\AA)$ & $10.9336(18)$ & $18.1712(12)$ & $9.6930(7)$ \\
$\alpha\left({ }^{\circ}\right)$ & $111.850(5)$ & & $63.119(2)$ \\
$\beta\left({ }^{\circ}\right)$ & $98.047(5)$ & & $66.836(2)$ \\
$\gamma\left({ }^{\circ}\right)$ & $103.885(4)$ & & $78.904(3)$ \\
$V\left(\AA^{3}\right)$ & $796.7(2)$ & $3994.4(4)$ & $570.25(8)$ \\
$Z$ & 2 & 8 & 2 \\
$D_{\text {calcd }}\left(\mathrm{g} \mathrm{cm}{ }^{-3}\right)$ & 1.193 & 1.092 & 1.486 \\
$\mu(\mathrm{Mo} \mathrm{K} \alpha)\left(\mathrm{cm}^{-1}\right)$ & 6.223 & 5.041 & 8.622 \\
$T\left({ }^{\circ} \mathrm{C}\right)$ & 4.0 & -100 & -150.0 \\
$\lambda(\mathrm{Mo} \mathrm{K} \alpha)(\AA)$ & 0.71075 & 0.71075 & 0.71075 \\
$R 1^{\mathrm{a}}$ & 0.0659 & 0.0592 & 0.0564 \\
$w R 2^{\mathrm{b}}$ & 0.2163 & 0.1899 & 0.1610 \\
\hline
\end{tabular}

${ }^{\mathrm{a}} R 1=\Sigma|| F_{\mathrm{o}}|-| F_{\mathrm{c}}|| / \Sigma\left|F_{\mathrm{o}}\right|$.

${ }^{\mathrm{b}} w R 2=\left[\sum w\left(F_{\mathrm{o}}{ }^{2}-F_{\mathrm{c}}{ }^{2}\right)^{2} / \Sigma w\left(F_{\mathrm{o}}{ }^{2}\right)^{2}\right]^{1 / 2}$. 
Table 2.

Selected bond lengths $(\AA)$ and angles (deg) for 1a, 1b, and 2a

\begin{tabular}{|c|c|c|c|}
\hline & 1a & 1b & $2 a$ \\
\hline \multicolumn{4}{|l|}{$\overline{\text { Bond Lengths }}$} \\
\hline $\mathrm{V}(1)-\mathrm{N}(1)$ & $1.680(5)$ & $1.660(2)$ & $1.691(5)$ \\
\hline $\mathrm{V}(1)-\mathrm{N}(3)$ & & & $2.196(4)$ \\
\hline $\mathrm{V}(1)-\mathrm{O}(1)$ & $1.899(4)$ & $1.793(2)$ & $1.847(4)$ \\
\hline $\mathrm{V}(1)-\mathrm{O}(2)$ & $1.800(3)$ & $1.777(2)$ & $1.835(4)$ \\
\hline $\mathrm{V}(1)-\mathrm{O}(3)$ & $1.808(5)$ & $1.775(2)$ & $1.859(5)$ \\
\hline$V(1)-O(1 a)^{a}$ & $2.179(4)$ & & \\
\hline $\mathrm{N}(1)-\mathrm{N}(2)$ & $1.321(8)$ & $1.316(4)$ & $1.311(7)$ \\
\hline \multicolumn{4}{|l|}{ Bond Angles } \\
\hline $\mathrm{V}(1)-\mathrm{N}(1)-\mathrm{N}(2)$ & $176.9(5)$ & $176.0(3)$ & $172.8(4)$ \\
\hline $\mathrm{N}(1)-\mathrm{V}(1)-\mathrm{N}(3)$ & & & $177.5(2)$ \\
\hline $\mathrm{N}(1)-\mathrm{V}(1)-\mathrm{O}(1)$ & $97.1(2)$ & $108.54(11)$ & $96.7(2)$ \\
\hline $\mathrm{N}(1)-\mathrm{V}(1)-\mathrm{O}(2)$ & $100.01(19)$ & $111.88(11)$ & $100.25(19)$ \\
\hline $\mathrm{N}(1)-\mathrm{V}(1)-\mathrm{O}(3)$ & $99.5(2)$ & $110.21(11)$ & $99.5(3)$ \\
\hline $\mathrm{N}(1)-\mathrm{V}(1)-\mathrm{O}(1 \mathrm{a})^{\mathrm{a}}$ & $169.82(19)$ & & \\
\hline $\mathrm{N}(3)-\mathrm{V}(1)-\mathrm{O}(1)$ & & & $80.79(16)$ \\
\hline $\mathrm{N}(3)-\mathrm{V}(1)-\mathrm{O}(2)$ & & & $81.19(15)$ \\
\hline $\mathrm{N}(3)-\mathrm{V}(1)-\mathrm{O}(3)$ & & & $81.61(17)$ \\
\hline $\mathrm{O}(1)-\mathrm{V}(1)-\mathrm{O}(2)$ & $116.61(19)$ & $108.00(10)$ & $122.28(18)$ \\
\hline $\mathrm{O}(1)-\mathrm{V}(1)-\mathrm{O}(3)$ & $121.30(16)$ & $108.96(10)$ & $115.35(18)$ \\
\hline $\mathrm{O}(1)-\mathrm{V}(1)-\mathrm{O}(1 \mathrm{a})^{\mathrm{a}}$ & $72.93(17)$ & & \\
\hline $\mathrm{O}(2)-\mathrm{V}(1)-\mathrm{O}(3)$ & $115.1(2)$ & $109.18(10)$ & $115.44(19)$ \\
\hline $\mathrm{O}(2)-\mathrm{V}(1)-\mathrm{O}(1 \mathrm{a})^{\mathrm{a}}$ & $86.78(16)$ & & \\
\hline $\mathrm{O}(3)-\mathrm{V}(1)-\mathrm{O}(1 \mathrm{a})^{\mathrm{a}}$ & $84.26(18)$ & & \\
\hline
\end{tabular}

a $-\mathrm{x}+1,-\mathrm{y},-\mathrm{z}$. 


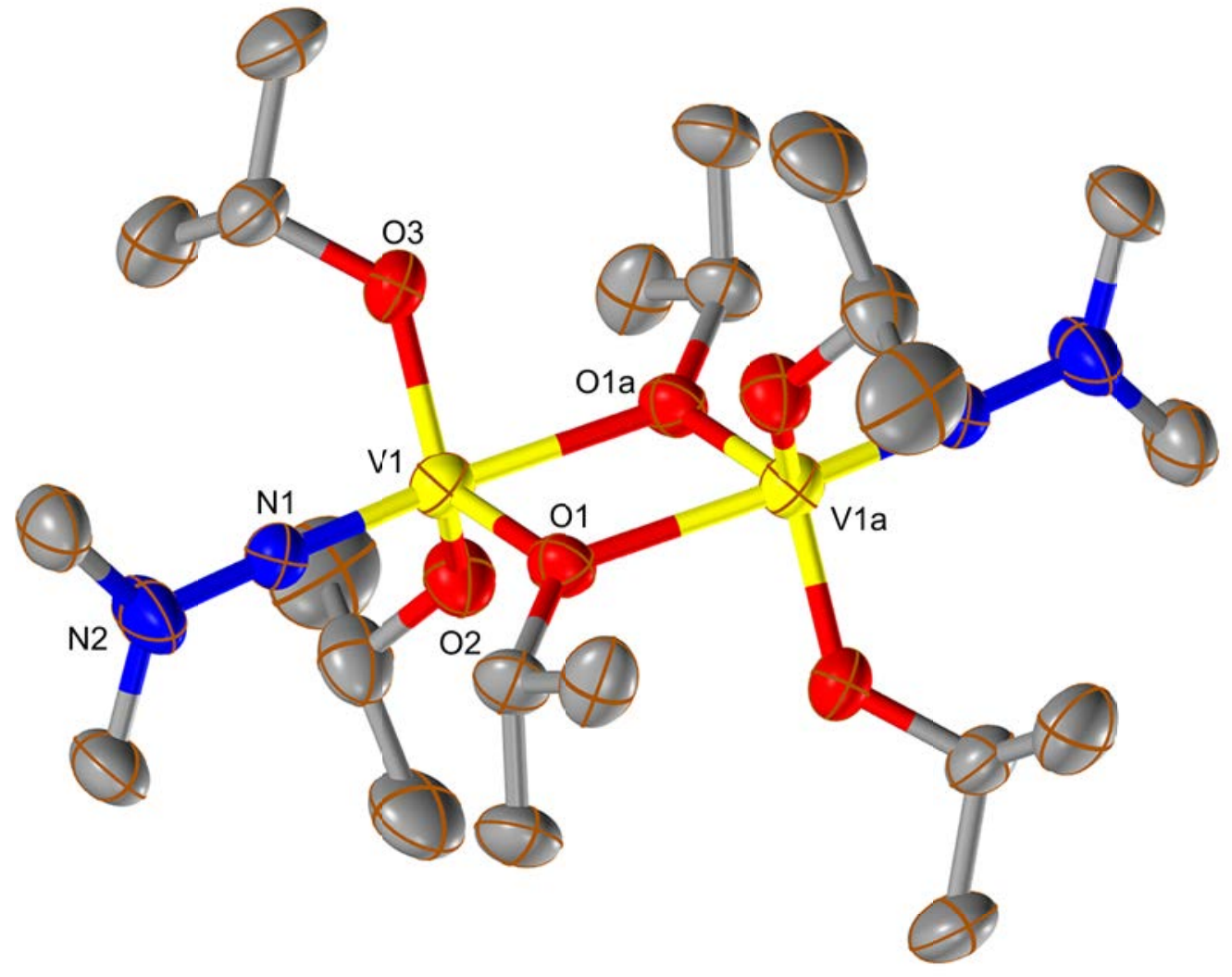

Figure 1 


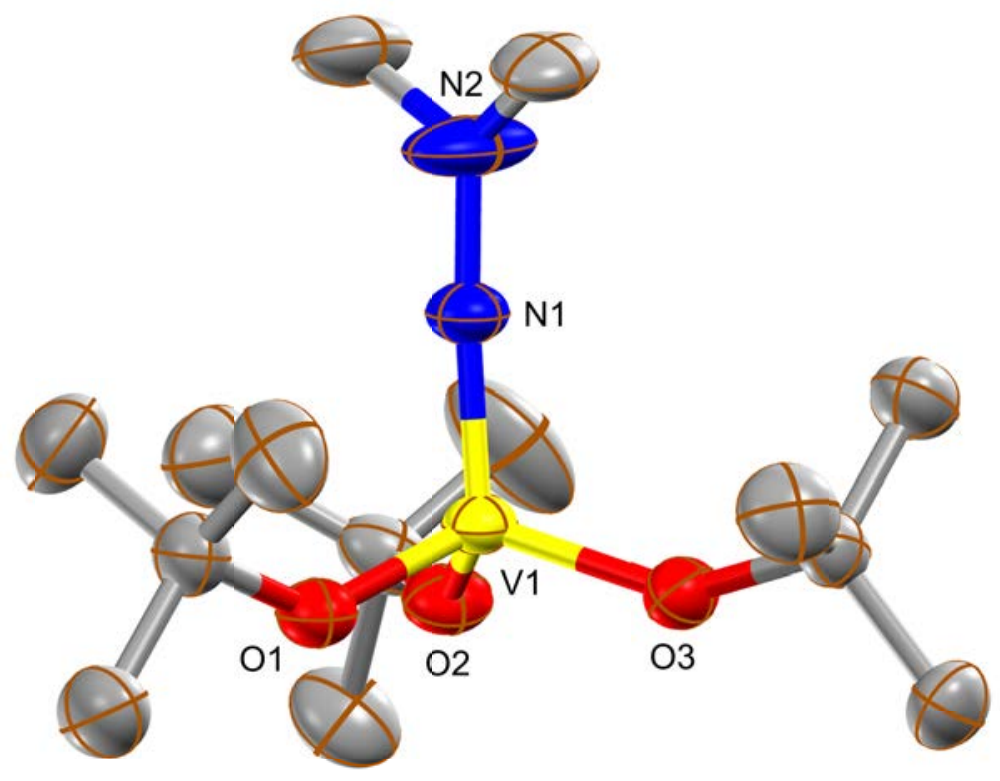

Figure 2 


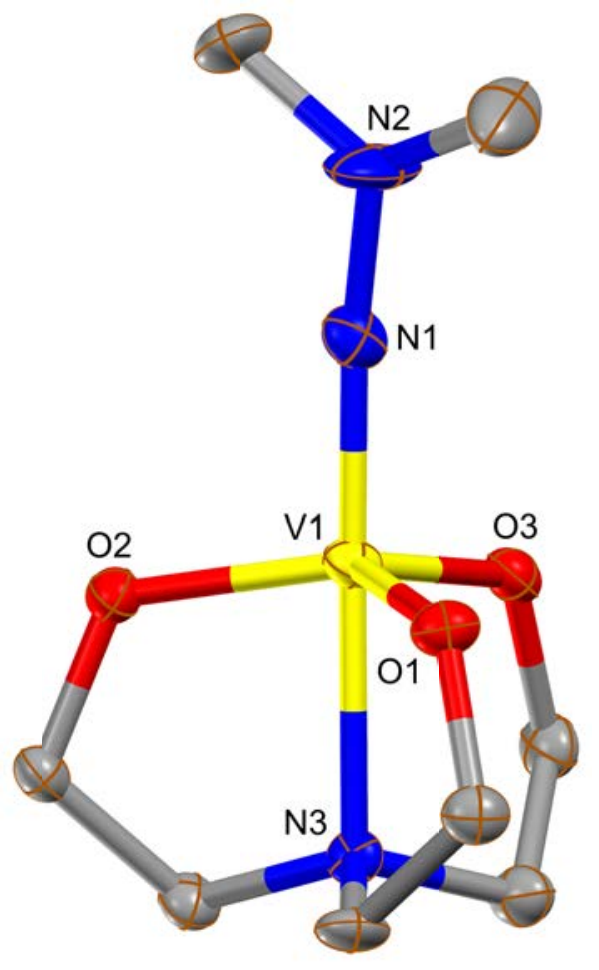

Figure 3 


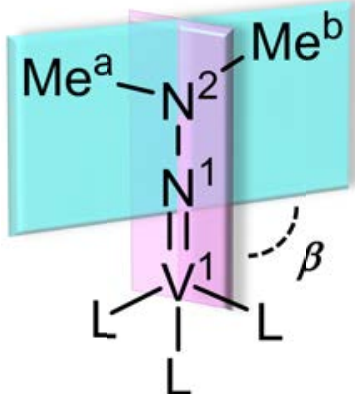

Figure 4 


\section{Graphical Abstract: Pictogram}

\section{Controlled Coordination in Vanadium(V) Dimethylhydrazido Compounds}

Takashi Sakuramoto, Toshiyuki Moriuchi,* and Toshikazu Hirao*

Department of Applied Chemistry, Graduate School of Engineering, Osaka University, Yamada-oka, Suita, Osaka 565-0871, Japan

Control of coordination environments of vanadium $(\mathrm{V})$ dimethylhydrazido compounds by changing alkoxide ligands was demonstrated to reveal the influence of the coordination from apical position on vanadium hydrazido.
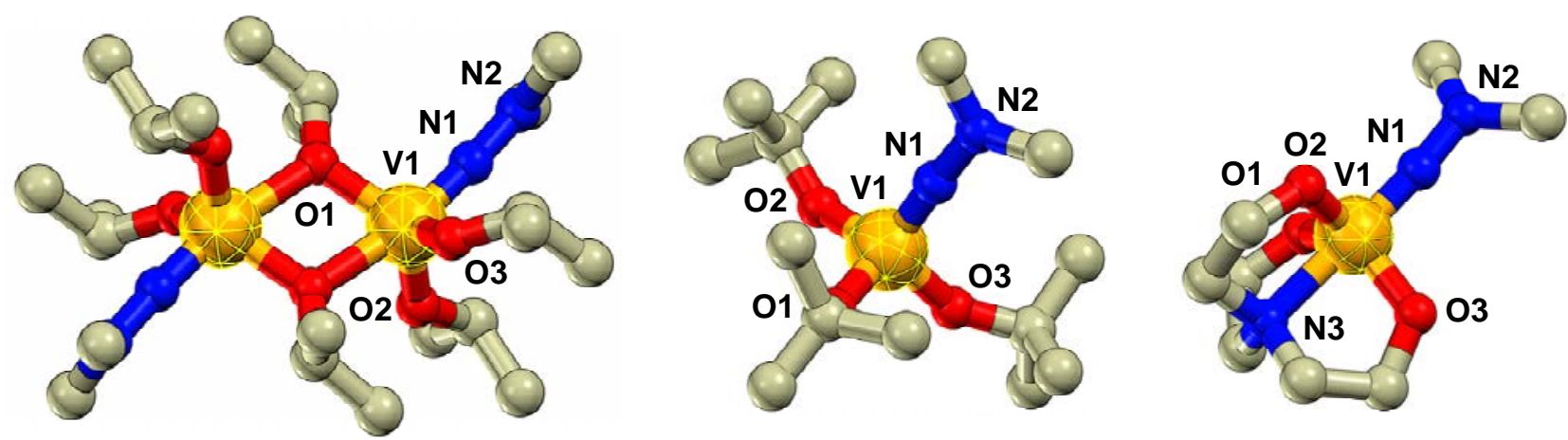